\title{
Comparison Between HER2, Estrogen Receptors and Progesterone Receptors in Primary Breast Carcinomas and Matched Lymph Node Metastases
}

\author{
Mohamed Mokhtar DESOUKI ${ }^{1}$, lhab Shafek ATTA², Daynna J WOLFF ${ }^{3}$, Sally E SELF \\ 'Department of Pathology, Microbiology and Immunology, Vanderbilt University School of Medicine, NASHVILLE, TN, UNITED STATES \\ Department of Pathology, ${ }^{2}$ Al Azhar University, Faculty of Medicine, Assuit Branch, EGYPT, ${ }^{3}$ Medical University of SC, CHARLESTON, SC, UNITED STATES
}

\section{ABSTRACT}

Objective: In the current work, we compared HER2 by fluorescence in situ hybridization and estrogen and progesterone receptors by immunohistochemistry in matched primary breast carcinomas and their lymph node metastases.

Material and Method: Thirty-nine cases of primary and lymph node metastases were assessed for HER2. Primary tumors of the cases selected were known to be HER2 negative. Also, immunohistochemistry for estrogen and progesterone receptors was performed on 36 cases from the same cohort to assess any discrepancy between the primary tumor and the lymph node metastases.

Results: Out of 39 cases, one case was HER2 amplified in lymph node metastasis compared to non-amplified primary tumor. Approximately eight percent of cases (3/36) were estrogen receptor-negative in LN metastasis and 5.55\% (2/36) were less strongly positive compared to the positive primary tumors. Nineteen percent $(7 / 36)$ were progesterone receptor-negative in lymph node metastasis in contrast to the matched positive primary tumors, and 5.55\% (2/36) were progesterone receptor-positive in lymph node as compared to their corresponding negative primary tumors.

Conclusion: While most matched primary breast tumors and lymph node metastases show concordance in HER2, estrogen and progesterone receptor status, we confirmed the multiple reports that identified discordant results in a subset of cases. These results support the newly adopted guidelines that require testing for HER2 on metastatic lesions.

Key Words: Estrogen receptor, Progesterone receptor, HER2, Breast cancer, Lymph node metastasis

\section{INTRODUCTION}

Estrogen (ER) and progesterone receptors (PR) are considered to be predictive markers for the patient response to hormonal therapy in breast cancer (1). In addition to its prognostic value, Human epidermal growth factor receptor (HER2) is an important predictive marker to predict the patient's response to Trastuzumab in mammary carcinomas. Trastuzumab is a humanized monoclonal antibody used, in combination with other drugs, in the treatment of HER2 positive breast carcinomas $(2,3)$. The American Society of Clinical Oncology (ASCO) and the College of American Pathologists (CAP) outlined guidelines for testing of HER2, ER and PR with continuous review and updates $(1,4,5)$. Currently these guidelines require HER 2 testing on metastatic and recurrent breast carcinomas $(6,7)$.

It has been published that approximately $20 \%$ of breast cancers are HER2 positive for gene amplification or show protein overexpression by immunohistochemistry

(Turk Patoloji Derg 2016, 32:178-185)

Received : 31.12 .2015 Accepted : 22.02.2016
(IHC) $(8,9)$. Therefore, determination of HER2 status is critical for patient care and for prediction of response to Trastuzumab. IHC and Fluorescence in situ hybridization (FISH) are the most commonly used methods for testing the HER2 status (5).

FISH analysis may be considered by some superior to that of IHC in predicting response to trastuzumab in patients with mammary carcinoma. This may be related to the strict criteria used as cut off in FISH analysis compared to the subjective analysis with personal variations in evaluating IHC results (10). However, others have reported that IHC is as effective as FISH in predicting the response to treatment (11). The concordance has been found to be high among IHC and FISH in negative ( 0 and $1+)$ and positive ( $3+)$ cases.

Steroid hormone receptors (ER and PR) are prognostic markers that determine to great extent the response to adjuvant hormonal therapy. It is the standard of care to test ER and PR in all cases of invasive breast carcinomas and to test ER in ductal carcinoma in situ (DCIS) $(5,12)$.

Correspondence: Mohamed Mokhtar DESOUKI

Department of Pathology, Microbiology and Immunology,

Vanderbilt University School of Medicine, NASHVILLE, TN, USA

E-mail: mokhtar.desouki@vanderbilt.edu Phone: +1 6153439540 
The data show that the expression of ER and PR is highly correlated between the primary tumors and their matched lymph node (LN) metastasis (13-16). Different scoring systems exist for evaluation of hormone receptor status (17). ASCO/CAP guidelines recommended a cut off as low as $1 \%$ to be considered positive for both markers by IHC (1).

The introduction of tamoxifen and trastuzumab has significantly altered the clinical outcomes of mammary carcinoma. Phenotypic inconsistency in ER, PR, and HER2 expression between the primary and metastatic site exists which leads to multiple clinical considerations. Testing the markers in the nodal or distant metastatic site in addition to testing in the primary tumor remains elusive. A metaanalysis addressing ER, PR, and HER2 expression in LN and distant metastases and in local recurrence showed multiple combination of inconsistency (18). These findings support the guidelines of evaluating the markers in metastasis and local recurrence.

Since breast cancer is a heterogeneous disease, it may be important to determine HER2, ER and PR status in LN metastases (19). Therefore, in this study, we compared HER2, ER and PR status between paired primary breast tumors and axillary $\mathrm{LN}$ metastases at our institution.

\section{MATERIALS and METHODS}

Breast Specimens: Specimens were obtained from 39 archived, formalin fixed, paraffin embedded tissue sections of LN metastasis from the Pathology Department at the Medical University of South Carolina, Charleston, SC. Selection was based on cases with known un-amplified HER2 on the primary tumor. This study was approved by the Medical University of South Carolina Internal Review Board.

Fluorescence in situ Hybridization: FISH was performed on the 39 blocks for the assessment of HER2 status. Slides were placed in xylene for $3 \times 5 \mathrm{~min}$, and dehydrated twice in two separate $100 \%$ ethanol baths for 5 minutes. Slides were then placed in a solution of $2 \mathrm{M} \mathrm{HCl}$ at room temperature for 20 minutes, rinsed for 1 minute in distilled water, and placed in the pre-treatment reagent $(1 \mathrm{M} \mathrm{NaSCN})$ at $80^{\circ} \mathrm{C}$ for 30 minutes, and rinsed with distilled water for 3 minutes. After pre-treatment, slides were placed in a $37^{\circ} \mathrm{C}$ solution of $0.2 \mathrm{M} \mathrm{HCl} / 4 \mathrm{mg} / \mathrm{ml}$ protease (Paraffin pre-treatment kit: Vysis, Inc.) for 10-20 minutes, and rinsed with distilled water for 3 minutes. After controlling digestion, slides were placed in 10\% neutral buffered formalin for 10 minutes and rinsed with distilled water. Dehydration was performed through graded alcohol (70\% ethanol, $85 \%$ ethanol, and $100 \%$ ethanol). Slides were then heated to $73^{\circ} \mathrm{C}$ on a hot plate with a $10 \mu \mathrm{l}$ probe for 5 minutes (Vysis multicolorprobe Topo IIa Spectrum Green, HER2 Spectrum Orange and CEP17 Spectrum Aqua). Slides were cover-slipped, sealed with rubber cement, and placed in a humid environment at $37^{\circ} \mathrm{C}$ for 16 hours. Coverslips were then removed by immersing slides in SSC/0.3\% Nonidet P-40 at $23^{\circ} \mathrm{C}$ for 2 minutes. Slides were then placed in another change of SSC $/ 0.3 \%$ Nonidet $\mathrm{P}-40$ at $73^{\circ} \mathrm{C}$ for 2 minutes, dried without light, and counterstained with $10 \mu \mathrm{l}$ of $0.2 \mu \mathrm{M}$ 4,6-diamidino-2-phenylindole (DAPI) in anti-fade solution (Vectashield: Vector Laboratories, Inc). Scoring is performed according to the CAP/ASCO 2010 guidelines (5) which were the guidelines at the time of performing the assay and before the new guidelines (4) have been released. In summary, amplified HER2 by FISH is considered with a ratio of HER 2 to CEP17 of $>2.2$ or average HER2 gene copy number of $>6$ signals/nucleus, equivocal result is defined as HER2/CEP17 ratio of 1.8-2.2 or average HER2 gene copy number of 4-6 HER2 signals/nucleus and non-amplified is defined as HER2/CEP17 ratio of $<1.8$ or average HER2 gene copy number of $<4$ (no Indeterminate case is encountered in the current cohort) (5). The same guidelines were followed at the time of assay for interpreting Her2 results by IHC in which positive results (3+) is defined as uniform intense membrane staining in $>30 \%$ of cells, equivocal $(2+)$ is defined as circumferential incomplete or weak staining in $>10 \%$ of cells or complete, circumferential staining in $\leq 10 \%$ of the cells and negative result if no staining (0) or weak incomplete membrane staining in any proportion of cells or weak, complete membrane staining in $<10 \%$ (5).

Immunohistochemistry (IHC): ER and PR IHC analysis was performed on serial tissue sections for only 36 of the cases from the same case cohort (the paraffin blocks were exhausted with no residual tissue left for the other 3 cases), the results of which were compared to that of the primary tumors. Paraffin slides were deparaffinized in two changes of xylene for 10 minutes each, and hydrated through graded alcohol and distilled water (2 changes of $100 \%$ ethanol, 2 changes of $95 \%$ ethanol, 2 changes of distilled water). Heat induced epitope retrieval with citrate buffer was performed. Slides were then cooled and rinsed with distilled water, rinsed in tris buffered saline with tween for 5 minutes. Slides were then rinsed with 3\% hydrogen peroxide, followed by rinse with wash buffer. Slides were then rinsed with wash buffer and covered with $300 \mu \mathrm{l}$ of protein block for 5 minutes. Following protein block, slides were treated with monoclonal anti-rabbit ER and PR Abs (NeoMarkers, Fremont, CA) used in 1:100 and 1:200 dilutions, respectively. Slides were then rinsed with wash buffer, and the secondary reagent Dako Envision labeled polymer HRP anti-Rabbit was applied. After the secondary reagent, $\mathrm{DAB}$ was applied for 10 minutes, and the slides were rinsed with distilled water. Counterstaining was done 
with hematoxylin for 3 minutes, and slides were washed in tap water. Slides were then blued in ammonia water, rinsed in tap water, dehydrated in graded alcohol (95\% ethanol, $100 \%$ ethanol), cleared in xylene (two changes), and coverslipped for microscopic examination.

With appropriate internal and external controls, positive ER or PR is considered if $\geq 1 \%$ of tumor cell nuclei are immunoreactive according to the guidelines (1). Allred scoring system is used in the current study. The score is assigned based on the summation of the proportion of positive cells $(0$ : no positive cells; $1=1 / 100 ; 2=1 / 10$; $3 ; 1 / 3 ; 4=2 / 3$ and $5=\sim$ all cells) and intensity of staining $(0=$ negative; $1=$ weak; $2=$ intermediate and $3=$ strong $)(17)$.

\section{RESULTS}

HER2 status in primary breast cancer compared to metastatic lymph node: One of the 39 cases was HER2 amplified in a nodal metastasis compared to the negative status in the primary tumor by FISH (Figure 1A-F). IHC was negative $(1+)$ in both primary tumor and the nodal metastasis (Figure 1A-F) (Table I).
ER status in primary breast cancer compared to metastatic lymph node: Most cases, 31 of 36 , show concordant ER status detected by IHC in LN metastasis as well as primary tumors, respectively (Figure 2A-F) (Table I). Three of 36 cases were ER negative in LN metastasis in contrast to the matched positive primary tumors (Figure 3A-F). Two of 36 the cases were positive in primary breast tumors (Allred score of $>2$ ) while the matched LN metastasis were ER-less strongly positive (Allred score of 1) (Figure 4A-F) (Table I).

PR status in primary breast cancer compared to metastatic lymph node: Most cases, 27 out of 36 , show concordant PR status detected by IHC in LN metastasis as well as primary tumors, respectively (Figure 2A-F) (Table I).

Seven of the 36 cases were PR negative in LN metastasis in contrast to the matched positive primary tumors (Figure 3A-F) (Table I). Two of the 36 cases were PR-negative in primary breast tumors while the matched $\mathrm{LN}$ metastasis were positive (Figure 4A-F) (Table I).
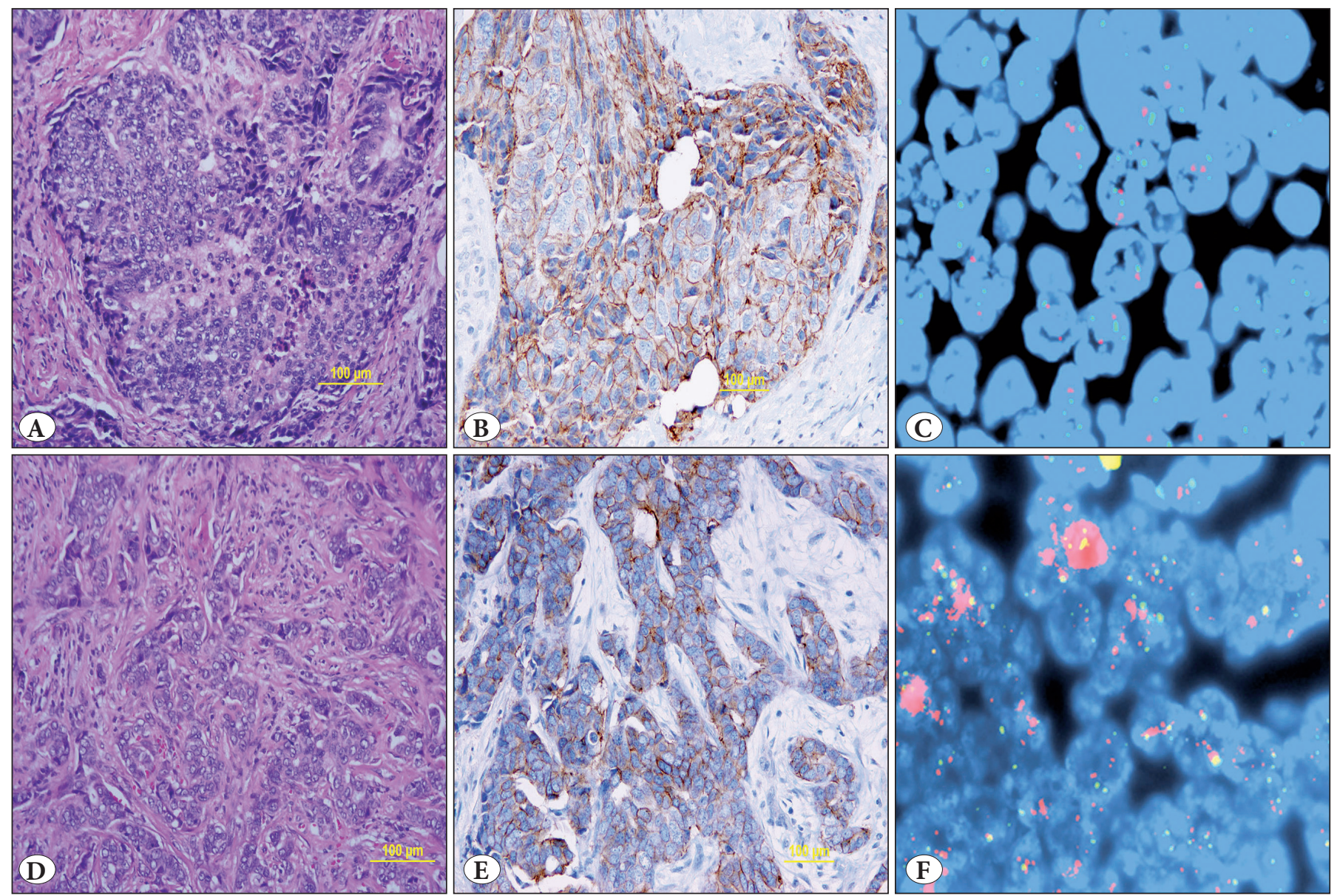

Figure 1: Case with amplified HER2 in lymph node metastasis compared to the primary tumor. Upper panel is the primary tumor and the lower panel is lymph node metastasis. A,D) (H\&E; x100), B,E) (IHC; x HER2) and C,F) (FISH; x HER2). 

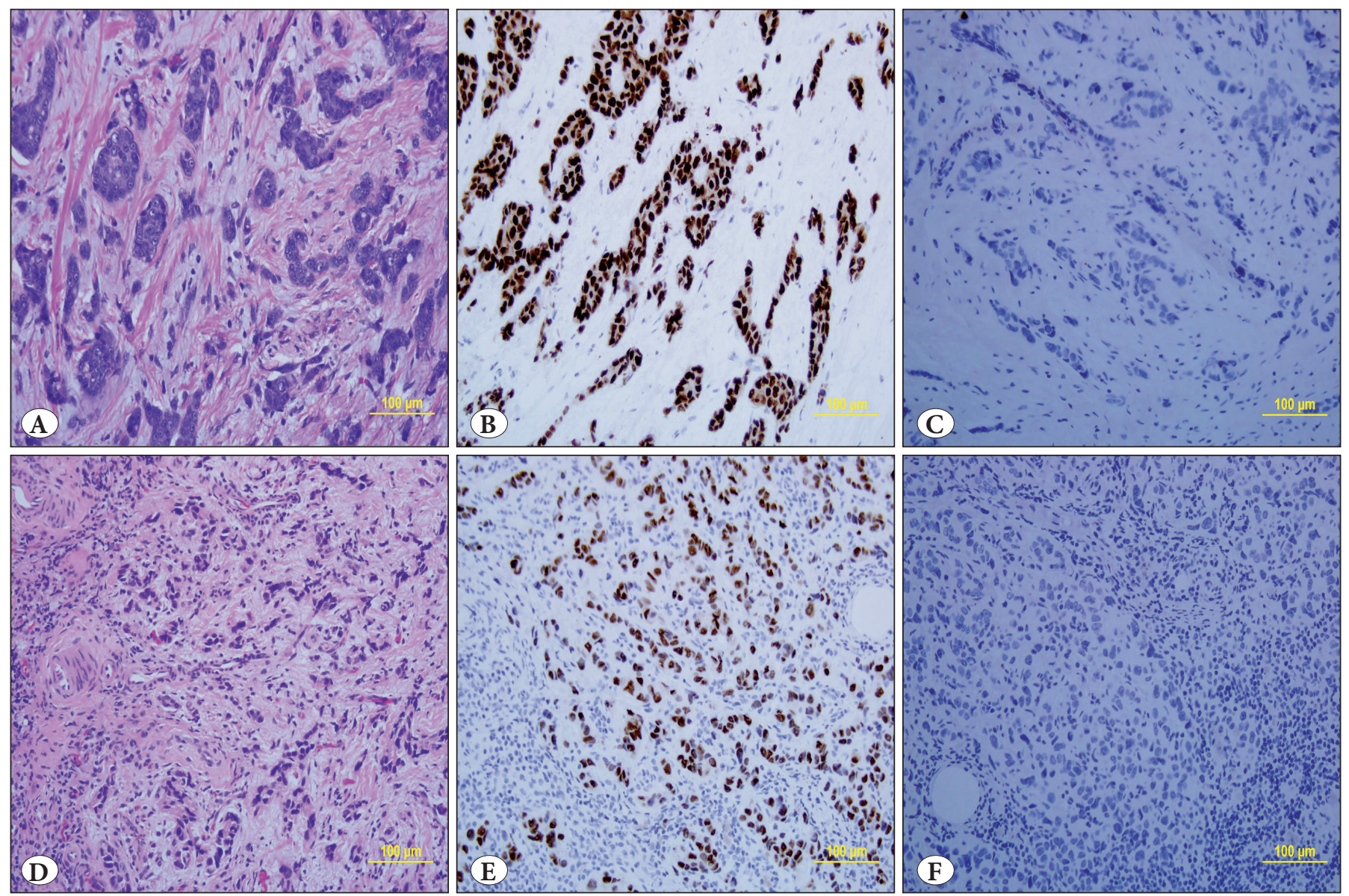

Figure 2: Case with concordant ER\&PR IHC in both primary tumor and lymph node metastasis. Upper panel is the primary tumor and the lower panel is LN metastasis. A,D) (H\&E; x100), B,E) (IHC; xER) and C,F) (IHC; xPR).

Table I: ER, PR and HER2 status in primary tumors and matched lymph node metastasis

\begin{tabular}{|l|c|c|c|c|c|c|c|}
\hline & & \multicolumn{7}{|c|}{ Primary tumor } \\
\hline & & \multicolumn{2}{|c|}{ ER IHC } & \multicolumn{2}{c|}{ PR IHC } & \multicolumn{2}{c|}{ HER2 FISH } \\
\hline \multirow{3}{*}{ ER IHC } & LN MET & Positive & Negative & Positive & Negative & Amplified & Non amplified \\
\cline { 2 - 8 } & Positive & 25 & 0 & & & & \\
\cline { 2 - 8 } & Negative & 3 & 6 & & & & \\
\cline { 2 - 8 } & Weak Positive & 2 & 0 & & & & \\
\hline \multirow{2}{*}{ PR IHC } & Positive & & & 15 & 2 & & \\
\cline { 2 - 8 } & Negative & & & 7 & 12 & & \\
\hline \multirow{2}{*}{ HER2 FISH } & amplified & & & & & 0 & 38 \\
\cline { 2 - 8 } & Non amplified & & & & & 0 & 3 \\
\hline
\end{tabular}

IHC: Immunohistochemistry, ER: Estrogen receptor, PR: Progesterone receptor, LN: Lymph node, Met: Metastasis, FISH: Fluorescence in situ hybridization

\section{DISCUSSION}

In the present study, we evaluated the HER2, ER, and PR status of primary breast tumors with their matched LN metastases using FISH and IHC techniques. Most published studies have evaluated the HER2 status in primary tumors only. However, others studied HER2 in primary and metastatic sites with inconsistent data. This 

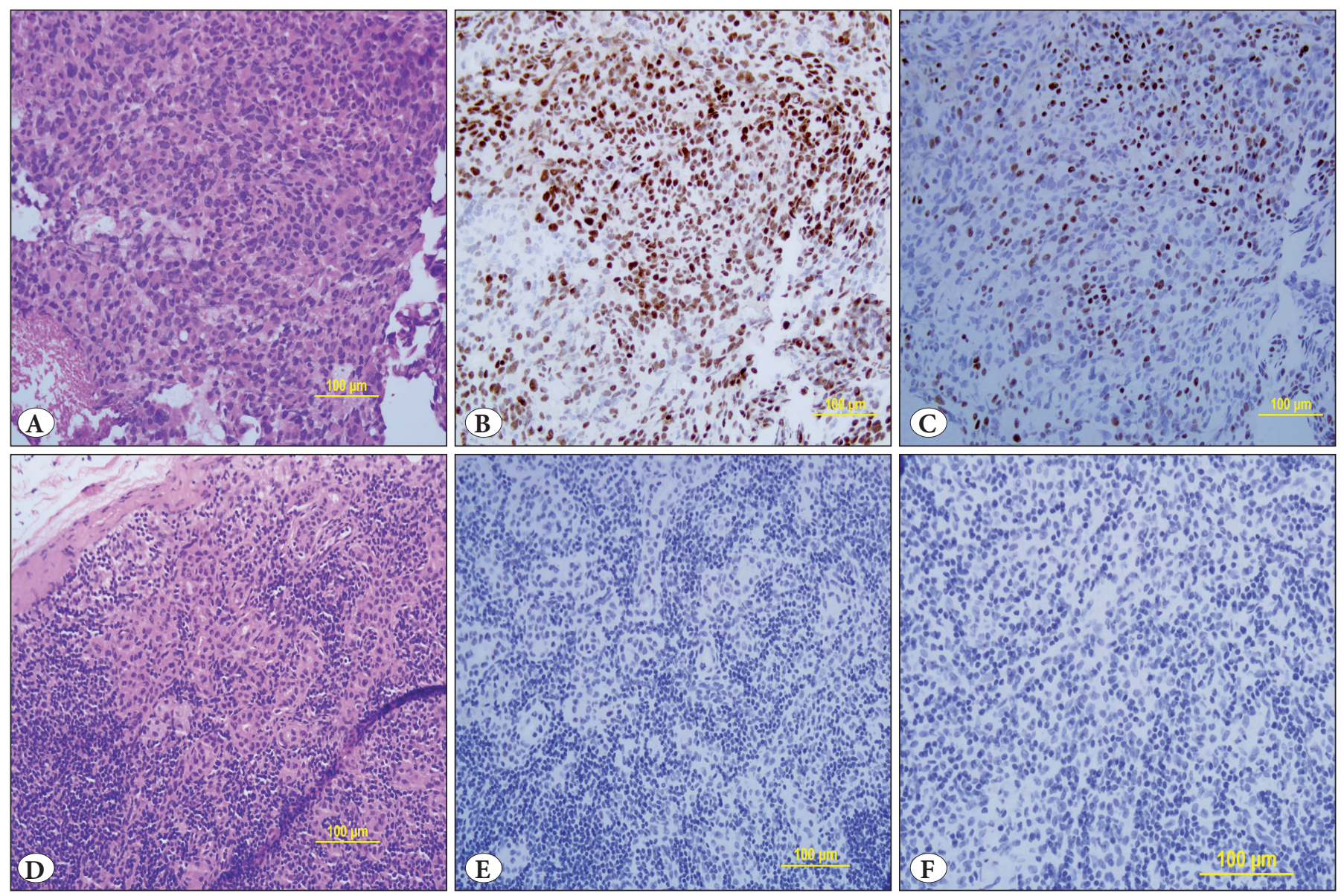

Figure 3: Case with positive ER and PR in primary tumor compared to negative LN metastasis. Upper panel is the primary tumor and the lower panel is lymph node metastasis. A,D) (H\&E; x100); B,E) (IHC; xER) and C,F) (IHC; xPR).

inconsistency may be attributed to tumor heterogeneity in primary versus metastatic sites (20-23).

In the current study, only one of the 39 cases with HER2 non amplified primary breast carcinoma showed amplified HER2 in the nodal metastasis. Likewise, a high concordance rate between primary breast tumors and matched LN metastasis have been reported by others $(24,25)$.

Niehans et al. compared HER2 expression in primary breast tumors in comparison to metastatic sites in autopsy samples from 30 decedents with known history of metastatic breast disease (26). This study documented 8 of these decedents was HER2 positive and, among those, there was a single case of discordant results. The authors concluded that HER2 expression is usually concordant between primary and metastatic sites. In agreement with our findings in the current report, Shimizu et al. evaluated HER2 protein, by IHC, in primary and metastatic breast cancer from 21 patients. The authors found no significant differences in the HER2 expression between the primary tumors and the nodal metastases (20). Masood et al. evaluated HER2 expression in 56 patients by IHC with 11 cases had distant site metastases. The score of the HER2 expression is identical in the primary tumors and the metastases with heterogeneity present in only one case (23).

Tanner et al. analyzed HER2 amplification in 46 primary mammary tumors and their matched metastases, using IHC and FISH techniques (22). The authors documented complete concordance regarding HER2 status between the primary tumors and the metastases. Gancberg et al. studied HER2 status in the primary and corresponding metastatic lesions and documented a high level of concordance (94\% and $93 \%$ when analyzed by IHC or FISH, respectively) (27). All discordant cases showed an increase in the staining intensity in the metastatic site. Among the discordant cases by FISH assay, 3 had HER2 gene amplified in the metastatic site, and the reverse (HER2 gene amplification in the primary tumor) in 2 cases.

Numerous studies have been done to evaluate the ER expression in both primary and metastatic carcinomas (2830). One study incorporated regional nodal and distant 

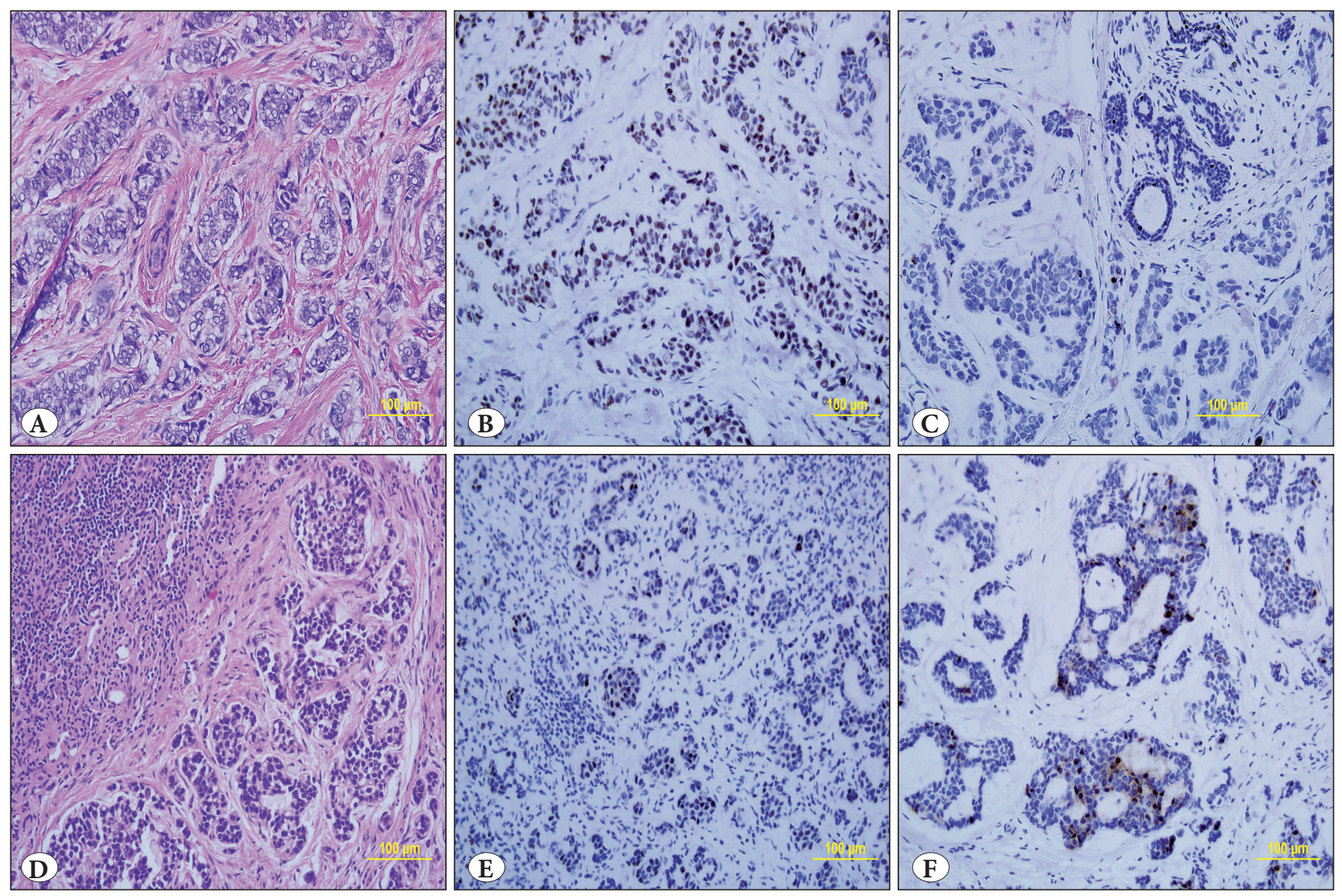

Figure 4: Case with positive ER and discordant PR by IHC in both primary tumor and LN metastasis. Upper panel is the primary tumor and the lower panel is lymph node metastasis. A,D) (H\&E; x100); B,E) (IHC; xER) and C,F) (IHC; xPR).

metastases as one group (28). In the present study, we found most cases, 31 of 36, show concordant ER status detected by IHC in LN metastasis as well as primary tumors. Three of 36 cases were ER negative in LN metastasis and two cases of 36 were less strongly positive for LN metastasis compared to the positive primary tumors. Preceding discordance rates for concurrent assays for ER diverge from $12 \%$ to $39 \%$, and PR discordance rates also varied from $14 \%$ to $32 \%$ (27-29) depending on the study and the assay utilized (30-33). Mobbs et al. reported 19\% and 33\% discordance of ER and PR between the primary and the metastatic tumors, respectively (34). Lower et al. established 30\% ER discordance and 19.5\% PR discordance between primary and metastatic tumors by IHC analysis (35). On the other hand, Idirisinghe et al. (36) demonstrated 18\% ER discordance and $42 \%$ PR discordance in metastatic lesions and $13 \%$ ER discordance (6/45) and 33\% PR discordance $(15 / 45)$ in locally recurrent lesions (36).
In conclusion, while most matched primary breast tumors and LN metastases show concordance in HER2, ER, PR status, we found discordance in a minority of cases. These results support the newly adopted guidelines of ASCO/ CAP to do HER2 studies in metastatic and recurrent breast tumors to guide further treatment options and predict prognosis in breast cancer patients.

\section{CONFLICT OF INTEREST}

The authors have no conflict of interest to declare.

\section{REFERENCES}

1. Hammond ME, Hayes DF, Dowsett M, Allred DC, Hagerty KL, Badve S, Fitzgibbons PL, Francis G, Goldstein NS, Hayes M, Hicks DG, Lester S, Love R, Mangu PB, McShane L, Miller K, Osborne CK, Paik S, Perlmutter J, Rhodes A, Sasano H, Schwartz JN, Sweep FC, Taube S, Torlakovic EE, Valenstein P, Viale G, Visscher D, Wheeler T, Williams RB, Wittliff JL, Wolff AC. American Society of Clinical Oncology/College of American Pathologists guideline recommendations for immunohistochemical testing of estrogen and progesterone receptors in breast cancer. Arch Pathol Lab Med. 2010;134:907-22. 
2. Gruver AM, Portier BP, Tubbs RR. Molecular pathology of breast cancer: The journey from traditional practice toward embracing the complexity of a molecular classification. Arch Pathol Lab Med. 2011;135:544-57.

3. Gruver AM, Peerwani Z, Tubbs RR. Out of the darkness and into the light: Bright field in situ hybridisation for delineation of ERBB2 (HER2) status in breast carcinoma. J Clin Pathol. 2010;63:210-9.

4. Hammond ME, Hicks DG. American Society of Clinical Oncology/College of American Pathologists human epidermal growth factor receptor 2 testing clinical practice guideline upcoming modifications: Proof that clinical practice guidelines are living documents. Arch Pathol Lab Med. 2015;139:970-1.

5. Wolff AC, Hammond ME, Hicks DG, Dowsett M, McShane LM, Allison KH, Allred DC, Bartlett JM, Bilous M, Fitzgibbons P, Hanna W, Jenkins RB, Mangu PB, Paik S, Perez EA, Press MF, Spears PA, Vance GH, Viale G, Hayes DF. Recommendations for human epidermal growth factor receptor 2 testing in breast cancer: American Society of Clinical Oncology/College of American Pathologists clinical practice guideline update. J Clin Oncol. 2013;31:3997-4013.

6. Niikura N, Liu J, Hayashi N, Mittendorf EA, Gong Y, Palla SL, Tokuda Y, Gonzalez-Angulo AM, Hortobagyi GN, Ueno NT. Loss of human epidermal growth factor receptor 2 (HER2) expression in metastatic sites of HER2-overexpressing primary breast tumors. J Clin Oncol. 2012;30:593-9.

7. Wilking U, Karlsson E, Skoog L, Hatschek T, Lidbrink E, Elmberger G, Johansson H, Lindstrom L, Bergh J. HER2 status in a population-derived breast cancer cohort: Discordances during tumor progression. Breast Cancer Res Treat. 2011;125:553-61.

8. Schechter AL, Hung MC, Vaidyanathan L, Weinberg RA, YangFeng TL, Francke U, Ullrich A, Coussens L. The neu gene: An erbB-homologous gene distinct from and unlinked to the gene encoding the EGF receptor. Science. 1985;229:976-8.

9. Akiyama T, Sudo C, Ogawara H, Toyoshima K, Yamamoto T. The product of the human c-erbB-2 gene: A 185-kilodalton glycoprotein with tyrosine kinase activity. Science. 1986;232:16446.

10. Owens MA, Horten BC, Da Silva MM. HER2 amplification ratios by fluorescence in situ hybridization and correlation with immunohistochemistry in a cohort of 6556 breast cancer tissues. Clin Breast Cancer. 2004;5:63-9.

11. Dressler LG, Berry DA, Broadwater G, Cowan D, Cox K, Griffin S, Miller A, Tse J, Novotny D, Persons DL, Barcos M, Henderson IC, Liu ET, Thor A, Budman D, Muss H, Norton L, Hayes DF. Comparison of HER2 status by fluorescence in situ hybridization and immunohistochemistry to predict benefit from dose escalation of adjuvant doxorubicin-based therapy in nodepositive breast cancer patients. J Clin Oncol. 2005;23:4287-97.

12. Dowsett M, Allred C, Knox J, Quinn E, Salter J, Wale C, Cuzick J, Houghton J, Williams N, Mallon E, Bishop H, Ellis I, Larsimont D, Sasano H, Carder P, Cussac AL, Knox F, Speirs V, Forbes J, Buzdar A. Relationship between quantitative estrogen and progesterone receptor expression and human epidermal growth factor receptor 2 (HER-2) status with recurrence in the Arimidex, Tamoxifen, Alone or in Combination trial. J Clin Oncol. 2008;26:1059-65.
13. Elledge RM, Green S, Pugh R, Allred DC, Clark GM, Hill J, Ravdin P, Martino S, Osborne CK. Estrogen receptor (ER) and progesterone receptor $(\mathrm{PgR})$, by ligand-binding assay compared with ER, PgR and pS2, by immuno-histochemistry in predicting response to tamoxifen in metastatic breast cancer: A Southwest Oncology Group Study. Int J Cancer. 2000;89:111-7.

14. Raica M, Cimpean AM, Ceausu RA, Fulga V, Nica C, Rudico L, Saptefrati L. Hormone receptors and HER2 expression in primary breast carcinoma and corresponding lymph node metastasis: Do we need both? Anticancer Res. 2014;34:1435-40.

15. Arapantoni-Dadioti P, Valavanis C, Gavressea T, Tzaida O, Trihia H, Lekka I. Discordant expression of hormone receptors and HER2 in breast cancer. A retrospective comparison of primary tumors with paired metachronous recurrences or metastases. J BUON. 2012;17:277-83.

16. Yao ZX, Lu LJ, Wang RJ, Jin LB, Liu SC, Li HY, Ren GS, Wu $\mathrm{KN}$, Wang DL, Kong LQ. Discordance and clinical significance of ER, PR, and HER2 status between primary breast cancer and synchronous axillary lymph node metastasis. Med Oncol. 2014;31:798.

17. Allred DC, Harvey JM, Berardo M, Clark GM. Prognostic and predictive factors in breast cancer by immunohistochemical analysis. Mod Pathol. 1998;11:155-68.

18. Jabbour MN, Massad CY, Boulos FI. Variability in hormone and growth factor receptor expression in primary versus recurrent, metastatic, and post-neoadjuvant breast carcinoma. Breast Cancer Res Treat. 2012;135:29-37.

19. Santinelli A, Pisa E, Stramazzotti D, Fabris G. HER-2 status discrepancy between primary breast cancer and metastatic sites. Impact on target therapy. Int J Cancer. 2008;122:999-1004.

20. Shimizu C, Fukutomi T, Tsuda H, Akashi-Tanaka S, Watanabe T, Nanasawa T, Sugihara K. c-erbB-2 protein overexpression and p53 immunoreaction in primary and recurrent breast cancer tissues. J Surg Oncol. 2000;73:17-20.

21. Cardoso F, Di Leo A, Larsimont D, Gancberg D, Rouas G, Dolci S, Ferreira F, Paesmans M, Piccart M. Evaluation of HER2, p53, bcl-2, topoisomerase II-alpha, heat shock proteins 27 and 70 in primary breast cancer and metastatic ipsilateral axillary lymph nodes. Ann Oncol. 2001;12:615-20.

22. Tanner M, Jarvinen P, Isola J. Amplification of HER-2/neu and topoisomerase IIalpha in primary and metastatic breast cancer. Cancer Res. 2001;61:5345-8.

23. Masood S, Bui MM. Assessment of Her-2/neu overexpression in primary breast cancers and their metastatic lesions: An immunohistochemical study. Ann Clin Lab Sci. 2000;30:259-65.

24. Lacroix H, Iglehart JD, Skinner MA, Kraus MH. Overexpression of erbB-2 or EGF receptor proteins present in early stage mammary carcinoma is detected simultaneously in matched primary tumors and regional metastases. Oncogene. 1989;4:14551.

25. Simon R, Nocito A, Hubscher T, Bucher C, Torhorst J, Schraml P, Bubendorf L, Mihatsch MM, Moch H, Wilber K, Schotzau A, Kononen J, Sauter G. Patterns of her-2/neu amplification and overexpression in primary and metastatic breast cancer. J Natl Cancer Inst. 2001;93:1141-6. 
26. Niehans GA, Singleton TP, Dykoski D, Kiang DT. Stability of HER-2/neu expression over time and at multiple metastatic sites. J Natl Cancer Inst. 1993;85:1230-5.

27. Gancberg D, Di Leo A, Cardoso F, Rouas G, Pedrocchi M, Paesmans M, Verhest A, Bernard-Marty C, Piccart MJ, Larsimont D. Comparison of HER-2 status between primary breast cancer and corresponding distant metastatic sites. Ann Oncol. 2002;13:1036-43.

28. Brennan MJ, Donegan WL, Appleby DE. The variability of estrogen receptors in metastatic breast cancer. Am J Surg. 1979;137:260-2.

29. Kuno K, Fukami A, Hori M, Kasumi F, Yoshimoto K. Factors affecting estrogen and progesterone receptors in primary breast cancer. Gan No Rinsho. 1983;29:621-7.

30. Kiang DT, Kennedy BJ. Factors affecting estrogen receptors in breast cancer. Cancer. 1977;40:1571-6.

31. Davis BW, Zava DT, Locher GW, Goldhirsch A, Hartmann WH. Receptor heterogeneity of human breast cancer as measured by multiple intratumoral assays of estrogen and progesterone receptor. Eur J Cancer Clin Oncol. 1984;20:375-82.
32. Hull DF 3rd, Clark GM, Osborne CK, Chamness GC, Knight WA 3rd, McGuire WL. Multiple estrogen receptor assays in human breast cancer. Cancer Res. 1983;43:413-6.

33. Gross GE, Clark GM, Chamness GC, McGuire WL. Multiple progesterone receptor assays in human breast cancer. Cancer Res. 1984;44:836-40.

34. Mobbs BG, Fish EB, Pritchard KI, Oldfield G, Hanna WH. Estrogen and progesterone receptor content of primary and secondary breast carcinoma: Influence of time and treatment. Eur J Cancer Clin Oncol. 1987;23:819-26.

35. Lower EE, Glass EL, Bradley DA, Blau R, Heffelfinger S. Impact of metastatic estrogen receptor and progesterone receptor status on survival. Breast Cancer Res Treat. 2005;90:65-70.

36. Idirisinghe PK, Thike AA, Cheok PY, Tse GM, Lui PC, FookChong S, Wong NS, Tan PH. Hormone receptor and c-ERBB2 status in distant metastatic and locally recurrent breast cancer. Pathologic correlations and clinical significance. Am J Clin Pathol. 2010;133:416-29. 